\title{
Well-being of Population Achieved Through Lifelong Education
}

\author{
Ruslan Aydarovich Garifullin \\ Medical Faculty \\ Bashkir State Medical University \\ Ufa, Republic of Bashkortostan, Russian Federation \\ e-mail: ruslanayd96@mail.ru
}

\author{
Elizaveta Andreevna Ganieva \\ Medical Faculty \\ Bashkir State Medical University \\ Ufa, Republic of Bashkortostan, Russian Federation \\ e-mail: $\underline{\text { liza81958@gmail.com }}$
}

\author{
Zulfiya Asgatovna Garifullina \\ Department of Humanities and Socio-Economic Sciences \\ Ufa State Petroleum Technological University, Branch of the University in the City of Oktyabrsky \\ Oktyabrsky, Republic of Bashkortostan, Russian Federation \\ e-mail: gza96@ya.ru
}

\begin{abstract}
The important area of modern medicine is the preservation of the reproductive health of women. To solve this problem, it is necessary to determine the levels of knowledge of modern methods of contraception and sexual literacy. The relevance of this issue is due to the low level of sexual education of the younger generation. The purpose of the article is to study the awareness of female workers of the Bashkir region of the Kuibyshev Railway of Russian Railways OJSC (Russian Railways OJSC) about modern methods of contraception and to assess the level of sexual literacy. The study was conducted on the basis of the Clinical Hospital of Russian Railways-Medicine (Ufa) in 2019 by surveying 30 female employees of the Russian Railways Company. The age of the respondents varied from 18 to 56 years (average age was 35.3 ). The survey was conducted anonymously, the respondents filled out a two-part questionnaire containing 41 questions. The analysis revealed that only $46.0 \%$ of women use effective methods of contraception. Despite this, respondents are well aware of hormonal contraception and have shown a satisfactory level of sexual literacy. Data analysis showed a good level of awareness of hormonal contraception, as well as a satisfactory level of sexual literacy. Despite this, only $46.0 \%$ of women use effective methods of contraception.
\end{abstract}

Keywords - well-being of the population, well-being of the nation, sexual literacy, contraception, reproductive health.

\section{INTRODUCTION}

One of the most important issues of modern medicine is the preservation of the reproductive health of women. The relevance of this issue is associated with a low level of sexual education of the younger generation. To solve this problem, it is necessary to determine the levels of knowledge of modern methods of contraception and sexual literacy, as well as to develop a number of social programs aimed at raising awareness.

Sexual education is a process of gender socialization that helps the child adopts the existing social rules of relationship between different sexes. Sexual education helps prepare a teenager for sexual life and contributes to reproductive health.

Based on the previous data, we can conclude that there is a tendency toward acceleration of physiological and sexual development, leading to an earlier formation of secondary sexual characteristics, and a decrease in the age of menstrual function. That is why it is so important to study the awareness of the population about possible methods of contraception. On the basis of the data obtained, it is necessary to develop an effective preventive program that identifies the most informative methods for communicating knowledge.

In the conditions of changing lifestyles of the modern generation associated with a decrease in public and social control over public health, media promote an "unhealthy" lifestyle. This deteriorates the social portrait of modern youth. Smoking, drinking alcohol, drugs and sexual activity are part of their lives.

The reducing age of physical puberty increased the period during which young people face sexual risks. The lack of awareness about diseases related to sexual life leads to their inadequate use of protective means and a rare access to medical care. Due to the underestimation of significance of the problem at the governmental level and among health workers, adolescents are often unable to obtain information. In recent years, reproductive health programs have begun to focus more on the needs of adolescents. It is necessary to take into account views of adolescents when developing programs for developing responsible behavior of young people in the reproductive sphere.

The term "sexually transmitted diseases" (STDs) appeared in 1982. This concept was used to refer to chlamydia, mycoplasmosis, viral diseases (herpes simplex virus, papilloma virus, hepatitis B virus, HIV), anaerobiosis, etc. (25 diseases). The incidence of STDs depends on education, the degree of socio-economic well-being. According to experts, every fifth inhabitant of the Earth suffers from STDs. We will 
study features of the spread of these diseases in Russia. Since 1990, the incidence of syphilis has increased by more than 50 times. Although in 1997, the annual growth rate significantly decreased in comparison with 1992-1995, when the number of sick people doubled annually, the number of cases still continues to grow; and secondly, it is a noticeable volume (277,3 per 100,000 of the population) and, thirdly, the incidence of syphilis is close to the epidemic threshold. Statistical data indicating a slight decrease in the incidence of gonorrhea since 1994 (in 1997, 114.2 people per 100,000 population) do not reflect the true prevalence of this disease due to the widespread use of self-medication, as well as treatment by private practitioners, not registering patients. The incidence rate of chlamydia is relatively low (106.1 per 100,000 of the population in 1996), although usually the number of patients with chlamydia is 2-2.5 times higher than the number of patients with gonorrhea. This disease develops with minimal clinical manifestations. It can last for years and cause profound changes in the genitourinary system. Many lesions are caused by viruses. The herpes simplex virus stimulates miscarriages, premature births and congenital malformations.

In general, the registration of infections of the so-called new generation began only in 1993. Peculiarities of the attitude of the Soviet health care system to sexually transmitted diseases still have a considerable effect on the spread of STDs in Russia. Venereology proceeded from the thesis: "Venereal diseases are not organically peculiar to socialist society. They exist insofar as survivals of capitalism are still alive in the minds of some people." The public system of combating sexually transmitted diseases was excessively brutal in relation to sick people. Until the 1970s, compulsory examination, compulsory treatment and criminal liability were provided. The consequences of this relationship have not yet been eradicated. This causes the patient's reluctance to be treated in medical institutions. Self-medication or contacting private practitioners are preferred. Currently, the main task of the venereological service is to restore public confidence. To this end, a system of anonymous examination and treatment of patients with STDs is developing. More than 300 anonymous examination rooms make it possible to provide emergency diagnostics, timely treatment, prevention of self-medication and patient access to non-specialists.

Despite these measures, a new outbreak of sexually transmitted diseases was recorded in the 1990s, which differs from previous outbreaks (in the 20th century, there were 4 of them, the last was in 1970). The growth of most STDs was highest in 1992-94. This process was facilitated by adverse social and economic phenomena (a decrease in living standards, migrants, an increase in the number of homeless, socially maladjusted people, etc.), as well as certain miscalculations in the organization of the healthcare sector (liquidation of the system that managed preventive measures and reduced the number of STDs; a decrease in alertness among medical personnel in relation to STDs due to the long period of low incidence of STDs; reduction in the share of preventive measures; the lack of propaganda of a healthy lifestyle, etc.). The new outbreak differs from the previous ones in that for the first time, children and adolescents were affected by these diseases, and their incidence is growing more rapidly than in adults (table). But before analyzing the spread of STDs in adolescence, it is necessary to consider the health characteristics of adolescents.

The study was conducted on the basis of the Clinical Hospital of Russian Railways-Medicine of Ufa in 2019 by surveying 30 female employees of Russian Railways. The age of the respondents varied from 18 to 56 years (average age 35.3). The survey was conducted anonymously, respondents filled out a two-part questionnaire containing 41 questions. The first part of the questionnaire included questions about education, income level, marital status, age of sexual activity, methods of contraception. The second part contained questions aimed at determining awareness of contraceptive methods and the level of sexual literacy. The condition for inclusion was voluntary consent to participate in the survey. Data processing was carried out by a statistical method using Statsoft Statistica 6.0. The analysis of the survey results revealed that only $46.0 \%$ of women use effective methods of contraception. Despite this, respondents are well aware of hormonal contraception and have shown a satisfactory level of sexual literacy. Most of the women surveyed spoke positively about early sexual education and reproductive health settings. To solve this issue, the authors suggest creating an information platform whose purpose is to disseminate high-quality knowledge among the population by specialists.

\section{RESULTS AND DISCUSSION}

At present, hormonal, barrier, intrauterine and other effective methods of contraception are available to the population [Medical criteria for the acceptability of contraceptive methods]. Despite this, contraception is not used properly. This may be due to the following reasons: the lack of awareness about methods and rules, a biased attitude to the use of a particular method of contraception, excessive persistence of a partner. Therefore, this issue remains relevant, social programs aimed at increasing sexual literacy of women of different ages have to be developed [1-3]

The result of sexual illiteracy is the early onset of sexual activity, the frequent change of sexual partners, the lack of intention to marry and start a family, and the widespread prevalence of artificial abortions.

Thus, the current situation is one of the main obstacles to the development of Presidential Decree No. 1351 of 09.10.2007 "On Approving the Concept of Russia's Demographic Policy until 2025." An important part of the concept of maintaining, restoring and strengthening reproductive health is development of positive reproductive attitudes, as well as increasing the level of sexual literacy among the younger generation [4].

In 2012, the journal "Protection of Maternity and Childhood" No. 2 published a study "Students' awareness of contraception and family planning," whose results show a high level of youth awareness of modern methods of contraception [5].

In 2016, the journal "International Journal of Applied and Fundamental Research" No. 5, published an article entitled 
"Contraception awareness of medical university students", whose results indicate a lack of awareness of modern methods of contraception, as well as a desire to receive additional information [6].

Based on the results, it can be concluded that the level of contraception awareness of women is average and the level of use of contraception methods is low. The level of sexual literacy of young people is low as well.

To study this issue, the questionnaire method was chosen. It allows finding out the opinion of respondents and assess their level of awareness.

According to the questionnaire, $46.6 \%$ of respondents have higher education, $40.0 \%$ - secondary vocational. $76.7 \%$ find their financial situation satisfactory, $16.7 \%$ - low, and only $6.6 \%$ - high. Most women were married $-70 \%$.

Of the women surveyed, $79.3 \%$ started a sexual life at 18 or more years, $17.2 \%$ - at $16-17$ years. When asked about the optimal age for sexual activity, $62 \%$ said that this was the age of $19-21,34.5 \%$ - 16-18. The survey found that $43.3 \%$ of women consider it necessary to care about reproductive health at an early age, $40.0 \%$ - in adolescence, $16.7 \%$ - after puberty.

The study found that $17.25 \%$ of women talked with parents about sexual education. In studies [6] and [7], the following results were obtained: $38.6 \%$ and $22.6 \%$, respectively. Unfortunately, there is a negative trend. At the same time, many women obtain information from third-party sources $[6,7]$, the level of practical application of knowledge remains insufficient ( $46 \%$ of respondents). It can be concluded that the amount of knowledge gained does not affect its practical application.

It is necessary to develop an information platform to increase the level of sexual education. The information provided by specialists should be based on evidence-based medicine and ensure its quality. This will entail an increase in the practical use of effective methods of contraception [8].

$93.1 \%$ of women consider abortion a hopeless situation, and medical indications and material conditions may be the justified cause of the abortion. This option was chosen by $86.1 \%$ of respondents. According to $58.6 \%$ of respondents, irresponsibility of people causes an increase in the number of abortions, $20.7 \%$ of women believe that the cause is poorly informed people, $10.3 \%$ of women deny the problem with abortions.

As for the contraceptive methods, the most popular method is birth control pills - 30\%; only $16.0 \%$ use the barrier method of contraception, the remaining share of women use ineffective methods of contraception, or they are not protected.

The reason for choosing these methods of contraception is reliability $-34.4 \%$, the lack of side effects - $18.5 \%$, other reasons - $25.9 \%$ (surgery, treatment, infertility). $44.4 \%$ of respondents consulted a medical professional when choosing a method of contraception, the remaining part of the women learned about them from other sources (media, Internet, partners).
As for their awareness of COCs (combined oral contraceptives), $64.3 \%$ of women consider COCs to be a reliable method of contraception, which does not increase weight $(58.5 \%)$, reduce libido $(57.1 \%)$ and lead to infertility (75.8\%); COCs cannot disrupt the menstrual cycle and make it irregular (66.6\%). $96.6 \%$ of women believe that it is necessary to consult a doctor when choosing a COC.

Female sexual literacy can be assessed by the following data: $90.0 \%$ and $86.2 \%$ of the respondents said that interrupted sexual intercourse and the calendar method are not reliable methods of contraception; you can become pregnant during breastfeeding $(90.0 \%)$, the first sexual intercourse (93.3\%). As for emergency contraception, $90.0 \%$ of women are convinced of dangers of this method and consider the acceptable frequency of its use 1-2 times a year (59.3\%) and once every three months $(22.2 \%) .83 .3 \%$ of women know the following STIs (sexually transmitted infections): syphilis, gonorrhea, HIV, chlamydia, genital herpes. Moreover, $48.3 \%$ believe that infection occurs with unprotected SI (sexual intercourse), $27.6 \%$ - with unprotected SI and blood transfusion. STI infection can be prevented by using a latex condom (48.3\%), abstinence and using a condom (33.4\%), and douching and using a condom (14.8\%).

Reproductive health is one of the most important components of human health, which affects the reproduction of the population and stability of the social system. Women have their own individual biological, psychological and social characteristics. In conditions of increasing intensity of life, any somatic disease, including that associated with the reproductive system, has a negative effect on the female wellbeing.

In the modern, ever-changing unstable environment, the issue of reproductive health is acute. Reproductive health is constantly confronted with negative environmental and social impacts. The desire of a woman to realize herself as a spouse and a parent is one of the fundamental needs. That is why it is important to develop priorities aimed at raising correct reproductive attitudes combined with a careful attitude to your health.

The importance of reproductive health occupies one of the leading places in the public policy dealing with the demographic situation in Russia. The reduction of reproductive losses and implementation of the reproductive potential of the population play an important role in ensuring the socio-demographic stability and national security of the country. This principle was established in the "Concept for the Reproductive Health of the Population of Russia for the Period until 2025" according to which health is one of the most important factors of the national security [9].

The health status of a woman is influenced by many factors: physical development of the female body with its inherent reproductive functions, socio-psychological needs and attitudes in the field of sexual and reproductive behavior, somatic health and awareness of gynecological morbidity, awareness of possible prevention methods, medical care, timely diagnosis, treatment, prevention of possible abnormalities in the reproductive sphere. 
In recent years, abortion prevention, as a method of family planning, has been regarded as the most important mechanism for resolving reproductive health problems.

According to modern data, the high frequency of abortions is one of the main methods of birth control. Only half of all pregnancies results in childbirth.

The use of modern contraceptives can reduce the number of unwanted pregnancies. Despite significant achievements in the field of birth control, Russia has not yet achieved the desired results. The reasons are the socio-economic situation and cultural characteristics. The main one is the negative attitude to hormonal contraceptives due to the lack of awareness of unwanted reactions, frequency of their occurrence and long-term effects.

The spread of hormonal contraception can reduce the number of abortions and improve quality of life, affect the life expectancy of the female population. Unfortunately, the results of this study show that this resource is not used to the full, which affects the demographic situation, and may affect the living standards due to an increase in the number of the old population [10].

It is necessary to improve the existing educational model aimed at increasing sexual literacy among the population. The main gaps are insufficient visibility, adherence to purely scientific rhetoric of the presentation of the material, which may not be clear to its target audience, the use of old methods of delivering information to the population. At the same time, it is necessary to pay attention to the fact that representatives of the medical sphere whose main tasks is sanitary and hygienic education, do not always cope with this task. We must not forget about the large amount of distorted information. [11].

It is necessary to create a modern educational strategy aimed at informing the population about modern methods of contraception, possible advantages and shortcomings based on evidence-based medicine. It is necessary to create conditions under which women will rely on comprehensive information. Due to this, the level of sexual literacy will be increased and conditions for strengthening reproductive health will be created. It will affect the performance in demographic policy and improve the well-being of citizens. Thus, the principle according to which the welfare of the country and its inhabitants depends on somatic and reproductive health will be strengthened [12].

In the era of digitalization and visualization of information, it is necessary to use these methods of presenting information. When the majority of the population is more or less concentrated on social networks (Vkontakte, Instagram, Facebook), the ability to broadcast information aimed at improving sexual literacy, informing about modern methods of contraception is the most promising and progressive. To achieve the greatest coverage of the population, it is necessary to take into account age characteristics and interests. Thus, it may be possible to disseminate information in the most efficient manner. Persons who will increase the level of medical literacy can be resident doctors, graduate students, senior students who will undergo preliminary testing, which will test their knowledge of modern contraception methods and give them the right to conduct such classes [13].

Despite the prevalence of remote forms of informing citizens about modern methods of contraception, social networks, we should not forget about elective classes in high schools, health lessons in schools, health camps, and teenage support centers. Doctors, graduate students, senior students can be invited which will help them improve their teaching skills, quality of theoretical and practical skills and ability to synthesize acquired knowledge and apply them in solving practical tasks.

\section{CONCLUSION}

Data analysis showed a high level of awareness of hormonal contraception, as well as a satisfactory level of sexual literacy. Despite this, only $46.0 \%$ of women use effective methods of contraception. The results are comparable with the works $[14,15]$

To increase the level of sexual literacy, awareness of contraceptive methods and greater implementation of a woman's life, it is necessary to develop an information platform whose purpose is to disseminate accessible information about modern methods of contraception, their advantages and disadvantages, methods of maintaining reproductive health. The initiators of development can be both higher medical institutions and consumers. It is also necessary to develop support centers for adolescents who need advice on contraception and reproductive health.

\section{References}

[1] Z.A. Garifullina, R.A. Garifullin and E.A. Ganieva, "On human welfare and health," Advances in Economics, Business and Management Research, vol. 113, pp. 541-544, 2019, January 2020. (FRED 2019, p. 559, 2019)].

[2] A.Y. Polyakov, "Full-fledged level of physical training of a specialist is an integral part of stability of a work process" SHS Web of Conferences, vol. 50, pp. 1-3, April 2018, (CILDIAH 2018, 2018) DOI: $10.1051 /$ shsconf/20185001218,

[3] E.R. Vasilyeva, A.R. Nurutdinova, "The academic model of managing integration processes: study case of the multicultural educational space," SHS Web of Conferences, vol. 50, pp. 1-3, April 2018, (CILDIAH 2018, 2018) DOI: $10.1051 /$ shsconf/20185001223

[4] R.C. Thurston, Y. Chang, P. Mancuso and K.A. Matthews, “Adipokines, adiposity, and vasomotor symptoms during the menopause transition: findings from the Study of Women's Health Across the Nation," Fertil Steril, vol. 100, pp. 793-800, 2013.

[5] E.A. Mukhtasarova and F.G. Safin, "State of modern russian youth tolerance," European Proceedings of Social and Behavioural Sciences, vol. 50, pp. 206-213, April 2018 (RPTSS 2018 p. 1464, 2018) DOI: 10.15405/epsbs.2018.12.26,

[6] J. Parsonnet, "Factors associated with disappearance of Helicobacter pylori in the West," Helicobacter pylori: Basic Mechanisms to Clinical Cure 2000, pp. 45-51, 2000.

[7] D.A. Schoenaker, C.A. Jackson, J.V. Rowlands, G.D. Mishra, "Socioeconomic position, lifestyle factors and age at natural menopause: a systematic review and meta-analyses of studies across six continents," Int J Epidemiol, 43, pp. 1542-1562, 2014.

[8] E.R. Vasilyeva and I.M. Sinagatullin, "Regional and ethnocultural specifics for developing intercultural and lingua-cultural competences: the pedagogical strategy," SHS Web of Conferences, vol. 50, pp. 1-4, April 2018, (CILDIAH-2018, p. 559, 2018) DOI: $10.1051 /$ shsconf/20185001222 
[9] E.A. Ganieva, Z.A. Garifullina, and R.A. Garifullin, "Health influence on life quality and social activities of women," Advances in Economics, Business and Management Research, vol. 113, pp. 313-316, May-June 2019 (FRED 2019)].

[10] G.A. Rosha and A.M.R. Oliveira, "Prevalence of Helicobacter infection in two different population," Helicobacter pylori: beginning the second decade, Houston, Texas, USA, 1994. Abstracts on disk TM from Astra/Merck.

[11] R.M. Shaidullina, A.F. Amirov, V.S. Muhametshin, and K.T. Tyncherov, "Designing Economic Socialization System in the Educational Process of Technological University," European Journal of Contemporary Education, vol. 6, no. 1, pp. 149-158, 2017, DOI: 10.13187/ejced.2017.1.149.

[12] M V Goryunova, L S Kuleshova, and A I Khakimova, "Application of signal analysis for diagnostics," 2017 International Conference on
Industrial Engineering, Applications and Manufacturing pp. 1795-1799, May 2017(ICIEAM, 2017) DOI: 10.1109/ICIEAM.2017.8076487

[13] R.N. Yusupov, "Resource of Russian religious and philosophical tradition in constructive relationship with west," European Proceedings of Social and Behavioural Sciences, vol. 50, pp. 1402-1408, April 2018 (RPTSS 2018, p.1464, 2018) DOI: 10.15405/epsbs.2018.12.171

[14] V.P. Smetnik et al., "Menopausal hormone therapy and preservation of health of women of Mature age. Menopause, Climacteric, vol. 4, pp. 8, 2014.

[15] S.S. Faubion, C.L. Kuhle, L.T. Shuster, W.A. Rocca, "Long-term health consequences of premature or early menopause and considerations for management," Climacteric vol. 18(4), pp. 483-491, 2015 